\title{
Predictors of poor responsiveness in physical rehabilitation centers in Tehran
}

\author{
Manijeh Alavi ${ }^{1,2}$, Maziar Moradi-Lakeh ${ }^{3}$, Ameneh Setareh Forouzan ${ }^{1}$, Homeira Sajjadi ${ }^{4}$, \\ Mohsen Shati ${ }^{5}$, Mohammad Reza Khodaie Ardakani ${ }^{1 *}$
}

\begin{abstract}
Background: Responsiveness as a nonmedical, nonfinancial aspect of a health system's goals requires special attention, particularly in people with physical disabilities. This study aimed to investigate the predictors of poor responsiveness of rehabilitation centers in Tehran.

Methods: A cross sectional study was conducted to investigate 610 individuals with physical disabilities who referred to 10 comprehensive rehabilitation centers in Tehran using Quota sampling in 2016-2017. The following questionnaires were used in this study: Health System Responsiveness questionnaire, recommended by World Health Organization (WHO); Activities of Daily Living (ADL); and Instrumental Activity of Daily Living (IADL). Multiple logistic regression models were used to determine the sociodemographic characteristics (sex, age, perceived social class, etc.), self-assessed health, and physical functioning [(eg, Instrumental Activities of Daily Living (IADL)] as predictors of poor responsiveness in comprehensive rehabilitation centers of Tehran.

Results: The mean years of education of respondents was $12.57(\mathrm{SD}=5.07)$. The majority of the participants perceived themselves as belonging to the middle class. Among the participants, $17.1 \%$ were completely dependent in their instrumental activities of daily living (IADL). Respondents who were not satisfied with their health insurance accounted for $40.2 \%$ of the sample. Also, 20.9\% of the participants reported poor responsiveness. Based on the logistic regression model, variables of education, perceived social class, satisfaction with health insurance, and IADL were predictors of overall poor responsiveness after adjusting other covariates.

Conclusion: Level of education was a strong predictor of poor responsiveness. Insurance companies should make policies to facilitate people's access to rehabilitation services and increase customer satisfaction. Moreover, rehabilitation service providers should pay special attention to those with physical disabilities who are more severely disadvantaged.
\end{abstract}

Keywords: Physical rehabilitation center, Poor responsiveness, Iran

Conflicts of Interest: None declared

Funding: None

\section{*This work has been published under CC BY-NC-SA 1.0 license. \\ Copyright $\odot$ Iran University of Medical Sciences}

Cite this article as: Alavi M, Moradi-Lakeh M, Setareh Forouzan A, Sajjadi H, Shati M, Khodaie Ardakani MR. Predictors of poor responsiveness in physical rehabilitation centers in Tehran. Med J Islam Repub Iran. 2019 (18 March);33:18. https://doi.org/10.47176/mjiri.33.18

\section{Introduction}

Responsiveness is one of the goals of health systems

Corresponding author: DrMohammad Reza Khodaie Ardakani, kh.ardakani@uswr.ac.ir

1. Social Determinants of Health Research Center, University of Social Welfare and Rehabilitation Sciences, Tehran, Iran

2. Deputy for Research and Technology, Ministry of Health and Medical Education, Tehran, Iran

3. Department of Community and Family Medicine, Preventive Medicine and Public Health Research Center, Iran University of Medical Sciences, Tehran, Iran

4. Social Welfare Management Research Center, University of Social Welfare and Rehabilitation Sciences, Tehran, Iran

5. Department of Aging, University of Social Welfare and Rehabilitation Sciences, Tehran, Iran and reflects nonmedical and nonfinancial aspects of health

$\uparrow$ What is "already known" in this topic:

In outpatient services, responsiveness to people with chronic illnesses (eg, mental disorders, diabetics, and heart failure) has been described, and predictors of poor responsiveness have been assessed in some studies (eg, perceived social class as the predictor of poor responsiveness of mental health services). However, few studies have been conducted on responsiveness to people with disabilities.

\section{$\rightarrow$ What this article adds:}

In addition to measuring the overall responsiveness level, predictors of overall poor responsiveness and poor performing domains, including basic amenities, choice, prompt attention, and autonomy, are reported in this study to provide evidence for further interventions to improve responsiveness. 
system performance (1). It is a relatively new concept that WHO has addressed since 2000 to assess the performance of health systems in member countries (2). Responsiveness relates to the individuals' experiences when they interact with the health system (1). It is a composite index proposed by WHO that includes 8 domains: (1) prompt attention, (2) clear communication, (3) dignity, (4) autonomy, (5) choice, (6) confidentiality, (7) quality of environment and basic amenities, and (8) access to social support (for patients admitted to hospitals). The WHO responsiveness module for assessing responsiveness includes several questions to assess these domains (3). Responsiveness relates to health promotion and all the functions of health systems, including prevention, rehabilitation, and curative activities (4). Responsiveness affects the well-being of people interacting with the health system. Good responsiveness seems to encourage people to refer to health services at an earlier stage. Furthermore, it relates to a better understanding of health information and results in improved compliance with instructions that can improve health outcomes (1). Therefore, research on poor responsiveness and its related factors is of particular importance.

Approximately $15 \%$ of the world's population are living with some type of disability. WHO recognizes disability as a human rights issue, a public health issue in the world and a development priority (5). People with disabilities are faced with more unmet needs in health issues than the general population (6). They experience widespread barriers to access health services; also, they have poorer health outcomes, lower education level achievement, and higher rates of poverty (5). There are less data on the health issues of people with disabilities than on those without disabilities. Several years after the adoption of the convention on the rights of people with disabilities, the gap in data on the health issues of people with disabilities is still considerable (7).

According to several reports in Iran, $4 \%-15 \%$ of people are suffering from some type of disability, especially physical disability (8-10). A large number of people with disabilities are living in Tehran, the capital of Iran (8). The rates of people with disabilities in Iran are increasing and require special attention (9). A number of studies on responsiveness of health systems and factors related to poor responsiveness to people suffering from other chronic disorders have been implemented in $\operatorname{Iran}(11,12)$. However, there is little information on health system responsiveness to people who use rehabilitation services in Iran. Considering this information gap, the purpose of this study was to investigate the factors associated with overall poor responsiveness of the health system to people with physical disabilities. In addition, this study aimed to examine predictors of poor responsiveness in domains which had weaker performance.

The results of this study may be useful for several groups. First, rehabilitation providers can identify poor performing domains and related predictors. Second, midlevel policymakers can use the findings for further interventions to improve responsiveness in rehabilitation centers. Finally, the study findings can help people with physical disabilities to gain a better understanding of the importance of responsiveness and factors that relate to their poor experiences in dealing with rehabilitation services.

\section{Methods}

This cross sectional study was conducted at comprehensive rehabilitation centers (CRCs) in Tehran from October 2016 to March 2017. All centers, private or public, must be licensed and supervised by a medical university. A list of all CRCs (31 centers) was obtained from 3 medical universities in Tehran. Of 31 centers, 18 were licensed in physical rehabilitation. Overall, 10 centers ( 5 public and 5 private) providing physical rehabilitation services were included in this study using Quota sampling (13). To select the centers, Tehran was divided into 5 districts (North, South, Center, West, and East) based on municipality borders. One public and 1 private comprehensive physical rehabilitation center were selected in each region. Lack of public CRC in the center and lack of interest of the only private CRC in south of Tehran to participate in the study led to replacing these $2 \mathrm{CRCs}$ with 2 referral CRCs that served clients in the mentioned regions. The geographic distribution of the centers made it possible to have clients from all districts of Tehran.

The proportion estimation formula was used to calculate the sample size (13). A total of 610 participants were interviewed in 10 selected centers. Monthly admission of clients was the basis for allocating the number of samples to each CRC. Inclusion criteria were age 18 years or over, a physical disability/impairment according to a physician's diagnosis, cognitively and physically capable to answer the questionnaire, and use of rehabilitation services in the last 12 months.

\section{Instruments}

Standard Health System Responsiveness Questionnaire proposed by WHO was used to assess responsiveness (14, 15). This questionnaire includes questions related to the use of service, general health, and responsiveness covering 8 domains ( 7 domains were considered for outpatient assessment). The domains were prompt attention (waiting time for receiving service in CRC), dignity (being treated respectfully), choice (meeting the rehabilitation provider of the choice), autonomy (participating in making decisions in rehabilitation process), confidentiality (experience of privacy regarding rehabilitation), clear communication (clarity of information received by rehabilitation provider), and basic amenities (cleanness and quality of environment). In each domain, there are 2 to 4 questions that reflect the individual's experiences with the health system and 1 rating question for the overall point of view of the patient, which is rated on a 5-point Likert scale, ranging from very good to very bad. According to cutoffs provided by $\mathrm{WHO}$, the performance of each responsiveness domain was considered as good if the response to the rating question of each domain was "very good or good" and as poor if the response was "any other". To determine the overall responsiveness, the scores of each domain were summed and their average was calculated, then, the scores 
were categorized into good (combining the very good and good) and poor responsiveness (combining moderate, bad, and very bad) (11). This questionnaire has previously been determined to be valid and reliable in Iran $(14,15)$. However, test-retest reliability test was performed and internal consistency of the questionnaire (Cronbach's Alpha) and internal correlation over time (Kappa) were calculated. Cronbach's alpha of the 7 domains showed the least range of 0.677 for prompt attention and the most of 0.911 for basic amenities. Kappa was at least 0.75 in prompt attention and at most 0.94 for basic amenities.

Activities of Daily Living (ADL) and Instrumental Activities of Daily Living (IADL) questionnaires were used to assess physical and instrumental functioning. ADL includes daily activities (walking, eating, dressing, grooming, etc.) and IADL contains instrumental daily activities (preparing meals, telephone use, travel in community, shopping, etc.). These questionnaires have previously been determined to be valid and reliable in Iran (16). There were 3 possible responses for each activity in both questionnaires: dependent, need help, and independent, which were scored as 0,1 , and 2 , respectively. The total scores for ADL and IADL were calculated for each respondent. In ADL, total scores of 0-7 were considered as completely dependent, 8-11 as partially dependent, and 12-16 as independent; in IADL, scores 0-6, 7-10, and 1114 indicated completely dependent, partially dependent, and independent, respectively (16). A demographic checklist was also completed.

Questionnaires and demographic checklist were administered by 2 interviewers, who were trained in a 4-hour training session, at the Institute for Humanities and Social Studies, along with the principal investigator.

\section{Terms and variables}

In this study, an individual with a physical disability was a person with musculoskeletal impairments or limitation of physical and/or instrumental activities who was referred by a physician to $\mathrm{CRC}$ to receive rehabilitation services during the data collection period.

Health system responsiveness was the outcome variable. Responsiveness was defined as a dichotomous variable (good as 0 and poor as 1$)(11,14)$.

An intensive literature search was performed to detect the independent variables that might have an association with poor responsiveness. The literature, including responsiveness texts of $\mathrm{WHO}$ and articles in international websites, such as ISI Web of Science, PubMed, and Scopus and Iranian websites, such as Magiran, were searched with no time limitation, and a list of related factors was extracted $(1,11,12,14,17-24)$. Then, 5 experts in the field of rehabilitation and responsiveness reviewed the list and proposed a series of 15 variables.

Center type was considered as public or private according to the lists obtained from 3 medical universities in Tehran (Iran University of Medical Sciences, Shahid Beheshti University of Medical Sciences, and Tehran University of Medical Sciences) in 2016. (14).

There was a question to specify gender (man or woman)
The question about age was asked by obtaining participants' birth date which was recoded in years and was dichotomized as $\geq 60$ and 18 -59 categories (14).

Self-assessed health was evaluated based on an answer to a question, which was rated on a 5-point Likert scale from very good to very bad. Participant's health was considered as "good health" if the response was good or very good and as "bad health" if the response was moderate, bad, or very bad (14).

Information about education was gathered by a question about the total completed years of education, which was categorized into 3 groups as $<5,5-12$, and $12<$ years (25).

Information on employment was collected based on an answer to a question and categorized the individuals into 3 groups: unemployed, employed without wage, employed with wage (25).

The perceived social class was determined by asking a question about the social class the participant perceives her/himself to belong (low, middle, or high class) (25).

Residential area per capita was assessed by 2 questions about the number of household members and the residence area $\left(\mathrm{m}^{2}\right)$; also, the ratio of residential area to household size was calculated and categorized as upper than median and under the median (26).

Information about health insurance was collected by a question about having a health insurance and a closed-end question about satisfaction with the insurance (Yes or No) (23).

Reason for physical disability was obtained by a question, which categorized the individuals into 3 groups as congenital, diseases, and accidents (27).

Information about duration of using rehabilitation services and disability in years was gathered by self-reports $(17,18)$.

Physical and instrumental functioning was determined by the scores of ADL and IADL questionnaires, categorizing individuals as dependent, need help, independent (16).

\section{Statistical analysis}

Categorical variables are presented as percentages, frequency, and median. Quantitative variables are presented as means and standard deviation (SD). Logistic regression (binary regression) was used to analyze the univariate association between responsiveness (dependent variable) and each of the independent variables. Independent variables that showed an association with responsiveness, with a significance level of 0.2 or less, were considered as input for the multiple logistic regression models.

The results of predictors are shown as odds ratio (OR) and $95 \%$ confidence interval (CI). Statistical significance was set at $\mathrm{P}$ value $\leq 0.05$. Statistical analysis was done by SPSS version 16 software.

\section{Ethical considerations}

The Ethical Committee of University of Social Welfare and Rehabilitation Sciences (ethical code: IR.USWR.REC.1395.86) approved this study. Also, the permission to implement this study was obtained from management boards of private and public centers and medical universities. 
Each referred client who met the inclusion criteria was informed of the goals and requirements of the study and was assured that the information would remain confidential. The client was included if he/she agreed to participate in the study and signed the informed consent.

\section{Results}

The mean age of men and women participating in the study was $45.6(\mathrm{SD}=15.4)$ and $46.4(\mathrm{SD}=14.3)$, respectively. The mean years of education of participants was $12.57(\mathrm{SD}=5.07)$, the mean of years living with physical disability was 5.45 years $(\mathrm{SD}=6.81$, median $=3)$, and the mean of years of using physical rehabilitation services was 3.51 years $(\mathrm{SD}=3.88$, median=2). A total of 375
$(61.5 \%)$ respondents reported that they usually use aiding tools for moving (wheelchair, walker, cane, etc.). The mean residential area was 108.4 square meter $(\mathrm{SD}=48.5$, median $=100)$, and the mean of residential area per capita was 40.57 ( $\mathrm{SD}=26.63)$. The mean of monthly rehabilitation costs was approximately $5400000(\mathrm{SE}=1100000$, median $=2000$ 000) Rials.

Poor responsiveness was reported by $20.9 \%$ of all respondents. However, $17.9 \%$ of the respondents who referred to private centers and $22.5 \%$ of those referring to public centers reported poor responsiveness.

Sociodemographic characteristics of the participants and the univariate relationship between each independent variable and poor responsiveness are presented in Table 1 .

Table 1. Socio-demographic characteristics of people with physical disability and association of the independent variables and poor responsiveness and unadjusted Odds Ratio (OR) in all the study CRCs

\begin{tabular}{|c|c|c|c|c|}
\hline Characteristic & $\begin{array}{c}\text { Frequency (Valid } \\
\text { Percentage \%) }\end{array}$ & Median & $\mathrm{p}$ & OR (Crude) \\
\hline & Center type & & & \\
\hline Private* & $204(34.3 \%)$ & & & \\
\hline Public & $406(65.7 \%)$ & & 0.19 & 1.3 \\
\hline \multicolumn{5}{|l|}{ Sex } \\
\hline Male * & $312(51.3 \%)$ & & & \\
\hline Female & $298(48.7 \%)$ & & 0.1 & 1.38 \\
\hline \multicolumn{5}{|l|}{ Age (years) } \\
\hline $18-59$ & $475(78.1 \%)$ & & 0.06 & 2 \\
\hline $60 \leq *$ & $133(21.9 \%)$ & & & \\
\hline Education & & & 0.11 & \\
\hline $5>$ (Elementary) & $20(3.3 \%)$ & & 0.99 & 0.000 \\
\hline 5-12 (Intermediate/High school) & $284(46.6 \%)$ & & 0.037 & 0.65 \\
\hline$>12$ (Upper) * & $305(50.1 \%)$ & & & \\
\hline \multicolumn{5}{|l|}{ Health status (self-report) } \\
\hline Good * & $90(14.9 \%)$ & & & \\
\hline $\mathrm{Bad}$ & $516(85.1 \%)$ & & 0.05 & 1.46 \\
\hline Perceived Social Class & & & 0.015 & \\
\hline Low & $139(22.9 \%)$ & & 0.12 & 2.28 \\
\hline Middle & $408(67.2 \%)$ & & 0.05 & 2.55 \\
\hline High * & $60(10.1 \%)$ & & & \\
\hline Employment & & & 0.29 & \\
\hline Unemployed & $73(12.4 \%)$ & & 0.23 & 1.4 \\
\hline Employed without wage & $216(36.5 \%)$ & & 0.53 & 0.87 \\
\hline Employed with wage* & $302(51.1 \%)$ & & & \\
\hline \multicolumn{5}{|l|}{ Having health insurance } \\
\hline Yes* & $562(93.7 \%)$ & & & \\
\hline No & $38(6.3 \%)$ & & 0.3 & 1.4 \\
\hline \multicolumn{5}{|l|}{ Satisfaction with health insurance } \\
\hline Yes* & $336(59.8 \%)$ & & & \\
\hline No & $226(40.2 \%)$ & & 0.001 & 1.99 \\
\hline Reason for physical disability & & & 0.065 & \\
\hline Disease * & $339(56.4 \%)$ & & & \\
\hline Accident & $244(40.6 \%)$ & & 0.02 & 1.59 \\
\hline Congenital & $18(3 \%)$ & & 0.25 & 1.85 \\
\hline Activities of Daily Living (ADL) & & & 0.93 & \\
\hline Dependent & $37(6.1 \%)$ & & 0.71 & 1.16 \\
\hline Help needed & $168(27.8 \%)$ & & 0.97 & 0.99 \\
\hline Independent * & $399(66.1 \%)$ & & & \\
\hline Instrumental Activities of Daily Living (IADL) & & & 0.65 & \\
\hline Dependent & $103(17.1 \%)$ & & 0.02 & 1.96 \\
\hline Help needed & $305(50.5 \%)$ & & 0.33 & 1.26 \\
\hline Independent * & $196(32.5 \%)$ & & & \\
\hline Duration of physical disability & & 3 & & \\
\hline Upper median & & & 0.94 & 1.01 \\
\hline \multicolumn{5}{|l|}{ Under median * } \\
\hline Duration of use of rehabilitation services & & 2 & & \\
\hline Years of using & & & 0.68 & 0.98 \\
\hline Residential area per capita & & 33.33 & & \\
\hline \multicolumn{5}{|l|}{ Upper median * } \\
\hline Under median & & & 0.049 & 1.5 \\
\hline
\end{tabular}


Variables such as center type, health status, sex, age, education, residential area per capita, perceived social class, satisfaction with health insurance, reason for physical disability, and IADL, which showed an association with responsiveness, at significance of 0.2 or less, were entered in a multiple regression model (Table 1).

The results of the multiple regression model are demonstrated in Table 2 based on adjusted odds ratio (OR) and $95 \%$ confidence interval.

Those with intermediate education (5-12 years of study) were approximately $44 \%$ less likely to report poor responsiveness (Table 2). When the perceived social class decreased from high to the middle level, it was 4 times more likely for people to experience poor responsiveness in dealing with CRCs. The likelihood of reporting poor responsiveness by those who were not satisfied with their health insurance was 2 times more than those who were satisfied with the service. Also, respondents who were classified as dependent in their instrumental daily activity were twice as likely to report poor responsiveness than those who were independent. These variables explained $11 \%$ of the variance of poor responsiveness in the studied samples.

Four domains, including basic amenities, choice, prompt attention, and autonomy, showed a poorer performance and fell below the median of overall responsiveness (4.28).

In the domain of prompt attention, the variables of satisfaction with health insurance, the reason of physical disability, duration of use of rehabilitation services, and IADL had a relationship with poor experience of respondents, with a significance level of $\leq 0.2$.

In the domain of autonomy, variables of center type, health status, perceived social class, satisfaction with health insurance, and duration of physical disability showed an association with poor experience at the significance level of $\leq 0.2$.

Variables as sex, education, employment, having health insurance, duration of using the rehabilitation services and ADL were associated with poor performance of the domain of choice at the significance level of $\leq 0.2$.

Except for employment and duration of use of rehabilitation services, all other independent variables in this study were associated with poor experience, with the quality of basic amenities at the significance level of $\leq 0.2$.

The results of multiple regression model showed that in the domain of prompt attention, the only predictor of poor responsiveness was satisfaction with health insurance.

Table 2. Multiple Regression models of predictors of poor responsiveness in all CRCs in Tehran

\begin{tabular}{|c|c|c|c|c|c|c|c|}
\hline \multirow{2}{*}{ Variable } & \multirow[t]{2}{*}{ OR } & \multirow[t]{2}{*}{$\mathrm{SE}$} & \multirow[t]{2}{*}{ Wald } & \multirow[t]{2}{*}{$\mathrm{df}$} & \multirow[t]{2}{*}{$\mathrm{p}$} & \multicolumn{2}{|c|}{ OR 95\% CI } \\
\hline & & & & & & Lower & Upper \\
\hline Education & & & 5.957 & 2 & 0.051 & & \\
\hline $5<$ (Elementary) & 0.000 & 10592.406 & .000 & 1 & 0.998 & 0.000 & 0.000 \\
\hline 5-12 (Intermediate) & 0.563 & 0.236 & 5.957 & 1 & $0.015 * *$ & 0.355 & 0.893 \\
\hline$>12$ (Upper) $*$ & 1 & & & & & & \\
\hline Perceived Social class & & & 8.693 & 2 & 0.013 & & \\
\hline Low & 2.531 & 0.605 & 2.357 & 1 & 0.125 & 0.773 & 8.280 \\
\hline Middle & 4.118 & 0.547 & 6.699 & 1 & $0.010 * *$ & 1.410 & 12.030 \\
\hline High * & 1 & & & & & & \\
\hline Satisfaction with health insurance & & & & & & & \\
\hline Yes * & 1 & & & & & & \\
\hline No & 2.169 & 0.228 & 11.496 & 1 & 0.001 & 1.386 & 3.394 \\
\hline $\begin{array}{l}\text { Instrumental Activities of Daily } \\
\text { Living (IADL) }\end{array}$ & & & 6.937 & 2 & 0.031 & & \\
\hline Dependent & 2.339 & 0.328 & 6.691 & 1 & $0.010 * *$ & 1.229 & 4.452 \\
\hline Help needed & 1.636 & 0.271 & 3.296 & 1 & 0.069 & 0.962 & 2.783 \\
\hline Independent * & 1 & & & & & & \\
\hline Constant & 0.046 & 0.576 & 28.399 & 1 & 0.000 & & \\
\hline
\end{tabular}

${ }^{*}$ Considered as reference group

** Significant $(\mathrm{p} \leq 0.05)$

Table 3. Multiple Regression model of predictors of poor experience of respondents in the domain of basic amenities in all CRCs in Tehran Predictors of poor experience in quality of basic amenities

\begin{tabular}{|c|c|c|c|c|c|c|c|}
\hline \multirow[t]{2}{*}{ Variable } & \multirow[t]{2}{*}{ OR } & \multirow[t]{2}{*}{$\mathrm{SE}$} & \multirow[t]{2}{*}{ Wald } & \multirow[t]{2}{*}{$\mathrm{df}$} & \multirow[t]{2}{*}{$\mathrm{p}$} & \multicolumn{2}{|c|}{ OR $95 \% \mathrm{CI}$} \\
\hline & & & & & & Lower & Upper \\
\hline Center type & & & & & & & \\
\hline Private ${ }^{*}$ & 1 & & & & & & \\
\hline Public & 1.968 & 0.244 & 7.712 & 1 & $0.005 * *$ & 1.220 & 3.172 \\
\hline Education & & & 11.933 & 2 & .003 & & \\
\hline $5<$ (Elementary) & 0.457 & 0.647 & 1.467 & 1 & 0.226 & 0.129 & 1.623 \\
\hline 5-12 (Intermediate) & 0.455 & 0.232 & 11.544 & 1 & $0.001 * *$ & 0.289 & 0.716 \\
\hline$>12$ (Upper) $*$ & 1 & & & & & & \\
\hline $\begin{array}{l}\text { Instrumental Activities of Daily } \\
\text { Living (IADL) }\end{array}$ & & & 11.278 & 2 & 0.004 & & \\
\hline Dependent & 1.539 & 0.355 & 1.477 & 1 & 0.224 & 0.768 & 3.086 \\
\hline Help needed & 2.539 & 0.287 & 10.554 & 1 & $0.001 * *$ & 1.447 & 4.456 \\
\hline Independent * & 1 & & & & & & \\
\hline Constant & 0.334 & 0.303 & 13.080 & 1 & 0.000 & & \\
\hline
\end{tabular}


Those dissatisfied with their insurance were twice more likely to report poor experience in the domain of prompt attention $(\mathrm{OR}=1.98 ; 95 \% \mathrm{CI}=1.07-3.67)$.

Self-report health status was a predictor of poor responsiveness in the domain of autonomy. Those who were identified as having bad health were more likely to experience poor responsiveness in this domain $(\mathrm{OR}=9.1 ; 95 \%$ $\mathrm{CI}+1.16-71.3)$.

The results of the multiple regression model of the predictors of participants' poor experience in the domain of basic amenities are displayed in Table 3.

Table 3 demonstrates that those who received rehabilitation services at public centers reported poor quality of basic amenities $97 \%$ more than those receiving services at private centers. People who needed help for their IADL reported poor quality of this domain 2.5 times more than those who were independent. People with intermediate education were $55 \%$ less likely to complain about the quality of basic amenities.

Table 4 shows the results of multiple regression model of the predictors of participants' poor experience in the domain of choice in this study.

In this domain, people with elementary education and those who were unemployed were, respectively, 15 and 4 times more likely to report poor experience compared to their reference group (Table 4).

\section{Discussion}

This study was conducted to find predictive factors for both overall poor responsiveness of CRCs in Tehran and the domains with poorer performance.

To the best of our knowledge, studies on this field are very rare. Thus, we compared our findings with those of studies conducted on other chronic diseases.

In this study, it was found that the percentages of women and men suffering from physical disability/impairment were almost equal. Approximately, half of the respondents reported no work-related income. Considering the mean monthly costs of rehabilitation and the mean age of respondents (around 46 years), this seems to be a warning sign, especially as $50 \%$ of respondents have been using rehabilitation services for more than 2 years.

The predictors of overall poor responsiveness in all studied CRCs in Tehran were education, perceived social class, satisfaction with medical insurance, and physical functioning as IADL.

In this study, people with an intermediate level of edu- cation were less likely to report overall poor responsiveness compared to those with higher levels of education. Also, in the predictors of poor performance of basic amenities domain, intermediate level of education of service users showed a protective effect for the poor experience of respondents. This might be due to higher expectations of people who had higher education. An investigation of Sajjadi et al in 2014-2015 showed that those diabetics with lower education level had a higher rate of reporting poor responsiveness in Tehran (12). However, in this study, elementary education was the predictor of poor responsiveness in the domain of choice. This indicates that people who had less than 5 years of education experienced difficulty in being able to choose their favorite center and use rehabilitation services. One explanation for this finding might be that people with a lower level of education may have less access to sources of information and usually have a lower level of health literacy $(28,29)$.

This study revealed that people reporting themselves as belonging to the middle social class were more likely to report poor responsiveness than those in a higher social class. The perceived social class was also introduced as a predictor of poor mental health responsiveness in Tehran by Forouzan et al research in 2016 (11), in which people in a low to middle social class were more likely to report poor responsiveness.

Having health insurance was one of the predictors in the research of Peltzer et al in South Africa in 2012 (23). WHO also reports that having private health insurance has a relationship with discrimination in the treatment of users (1). A study in Thailand in delivery care in 2012 showed that type of health insurance was significantly related to responsiveness (24). The present study showed that people who were less satisfied with their health insurance had a poorer experience when they were referred to rehabilitation services. Also, in this study, this relationship was associated with poor performance of prompt attention, indicating that people who are less satisfied with their health insurance believed they experienced longer wait times and limited access to rehabilitation services. This finding explains how less satisfaction with insurance can affect responsiveness.

Less functional capability in terms of being dependent in IADL was a predictor of poorer experience compared to people who could independently accomplish their instrumental activities of daily living. If we consider the predictors of poor responsiveness in the domain of basic ameni-

Table 4. Multiple Regression model of predictors of poor experience of respondents in the domain of choice in all CRCs in Tehran

\begin{tabular}{|c|c|c|c|c|c|c|c|}
\hline \multicolumn{8}{|c|}{ Predictors of poor experiencing in choice } \\
\hline \multirow{2}{*}{ Variable } & \multirow{2}{*}{$\mathrm{OR}$} & \multirow[t]{2}{*}{$\mathrm{SE}$} & \multirow[t]{2}{*}{ Wald } & \multirow[t]{2}{*}{$\overline{d f}$} & \multirow[t]{2}{*}{$\overline{\mathrm{p}}$} & \multicolumn{2}{|c|}{ OR $95 \% \mathrm{CI}$} \\
\hline & & & & & & Lower & Upper \\
\hline Education & & & 5.212 & 2 & 0.074 & & \\
\hline $5<$ (Elementary) & 15.649 & 1.217 & 5.105 & 1 & $0.024 * *$ & 1.440 & 170.108 \\
\hline 5-12 (Intermediate) & 1.029 & 0.406 & 0.005 & 1 & 0.944 & 0.464 & 2.281 \\
\hline$>12$ (Upper) * & 1 & & & & & & \\
\hline Employment & & & 6.693 & 2 & .035 & & \\
\hline Employed with wage * & 1 & & & & & & \\
\hline Employed without wage & 2.239 & 0.468 & 2.972 & 1 & 0.085 & 0.895 & 5.598 \\
\hline Unemployed & 4.008 & 0.545 & 6.484 & 1 & $0.011 * *$ & 1.377 & 11.669 \\
\hline Constant & 0.096 & 0.385 & 37.117 & 1 & 0.000 & & \\
\hline
\end{tabular}

*Considered as reference group

** Significant $(\mathrm{p} \leq 0.05)$ 
ties, people who need help in their IADL also report a poorer performance. One possible explanation may be that these people are less functional and might suffer from a severe form of physical disability or impairment that needs special attention to adequate environment and enough space for moving, especially with an attendant. Fiorentini showed that less healthy patients with more pain were more likely to report poor responsiveness (30). Likewise, in this study, people with worse perceived health status had a poorer experience in the domain of autonomy and believed they have not participated enough in rehabilitation activities. Another explanation would be based on health selection hypothesis which refers to the possibility of health as a determinant of socioeconomic status. Disorders and diseases, especially if long-term and chronic, affect the employment and income of a person who will more likely to be disadvantaged. According to the theory of social Darwinism, people's access to higher incomes and jobs is done in a selective process in which more healthy people are more likely to succeed. Consequently, people with lower socioeconomic status may suffer from less access to qualified services $(31,32)$.

The center type (public or private) was one of the predictors of poor responsiveness in the domain of basic amenities, as people referred to public centers were about twice more likely to complain about the cleanliness and environment of the CRC. This may be related to the fact that public centers are usually older and less renovated with more referred clients. Furthermore, private centers usually modernize the building and try to make the clients satisfied with the environment, as rehabilitation activities are continuous. This finding has also been observed in a study in Thailand, in which poor responsiveness was more likely to be reported in all the domains by people who used public centers (24).

One interesting finding was that people who were unemployed were 4 times more likely to have poorer experience in the domain of choice. One possible explanation is that unemployed people are more likely to have less income, so they would have limited choices.

Study limitations: This study faced some limitations. Failure to enter the public rehabilitation center from center district and disagreement of the only private rehabilitation center in south of Tehran for participating in the study were limitations that led to replacing these CRCs with 2 other CRCs that served referral clients in the mentioned regions, which almost covered this limitation.

In this study, individuals who did not use rehabilitation services were excluded.

Also, the participants were not screened for diseases and health assessment was based on self-report.

\section{Conclusion}

Findings of this study suggested that education level, satisfaction with health insurance, and functional capability of the people with physical disability were strong predictors of responsiveness.

It is important for providers of rehabilitation services to acknowledge that people with physical disabilities who have higher education levels expect better treatment and a better environment when they use rehabilitation centers. This may be due to the difference between the standards of these clients compared to other users with lower education levels.

Insurance companies are indirectly involved in the rehabilitation process. Thus, they should be aware that their action in terms of providing access to rehabilitation centers has an important role in the experience of people when interacting with health system.

Also, providers of rehabilitation services should acknowledge that clients with physical disabilities who have fewer functional capabilities and are less healthy need more attention, particularly in terms of quality of environment, and they should be involved in the decisions made about their rehabilitation process.

\section{Acknowledgments}

This article was derived from a Ph.D. thesis on responsiveness led by University of Social Welfare and Rehabilitation Sciences. We acknowledge and appreciate this university for its supports.

Also, we would like to thank all the comprehensive rehabilitation centers and participants who contributed to this study.

\section{Conflict of Interests}

The authors declare that they have no competing interests.

\section{References}

1. Valentine NB, de Silva A, Kawabata K, Darby C, Murray CJ, Evans DB. Health system responsiveness: concepts, domains and operationalization. In: Murray CJ, Evans DB, editors. Health systems performance assessment: debates, methods and empiricism. Geneva: World Health Organization; 2003.pp.573-96.

2. Ristea AL, Ioan-Franc V, Valeriu LF, Dinu V. Responsiveness of health systems: a barometer of the quality of health services. Amfiteatru Economic. 2009;11(26):277-87.

3. Fazaeli S, Ahmadi M, Rashidian A, Sadoughi F. A Framework of a Health System Responsiveness Assessment Information System for Iran. Iran Red Crescent Med J. 2014; 16(6):e17820

4. de Silva A, Valentine N. Measuring responsiveness: results of a key informants survey in 35 countries. Geneva: World Health Organization; 2000.pp.1-36.

5. World Health Organization. Draft WHO global disability action plan 2014-2021: Better health for all people with disabilities. Geneva: World Health Organization; 2015.pp.1-25

6. Krahn GL. WHO world report on disability: a review. Disabil Health J. 2011;4(3):141-2.

7. Mitra S. Data revolution for disability-inclusive development. Lancet Glob Health. 2013;1(4):e178-9.

8. Ramazani Ghavamabadi M. The Protection of Disable People in the International Law. Social Welfare Quarterly. 2011;11(41):307-41.

9. Moore A, Kornblet S. Advancing the Rights of Persons with Disabilities: A US-Iran Dialogue on Law, Policy, and Advocacy. Washington DC: The Henry L. Stimson; 2011.pp.1-79.

10. Shirazikhah M, Mirabzadeh A, Sajadi H, Joghataei MT, Biglarian A, Mousavi T, et al. National survey of availability of physical rehabilitation services in Iran: A mixed methods study. Electron Physician.2017;9(11).5778-86.

11. Forouzan S, Padyab M, Rafiey H, Ghazinour M, Dejman M, San Sebastian M. Measuring the mental health-care system responsiveness: results of an outpatient survey in Tehran. Front Public Health. 2016;(3):285.

12. Sajjadi F, Moradi-Lakeh M, Nojomi M, Baradaran HR, Azizi F. Health system responsiveness for outpatient care in people with diabetes Mellitus in Tehran. Med J Islam Repub Iran. 2015;(29):293- 
305.

13. rafeiey. H, Sajadi. H, Narenjiha. H, Nouri. R, Farhadi. MH, Shirinbayan. F. Qualitative and quantitative methods in addiction and the social problems and deviances. Tehran: Danjeh; 2008.pp.528.

14. Valentine N, La Vallée R, Letkorvicova H, Prasad A, Adhikari P, Van der Heide GW. The Health Systems Responsiveness Analytical Guidelines for Surveys in the Multi-country Survey Study. Geneva: World Health Organization; 2005.pp.1-140.

15. Asghari S, MalekAfzali H, Majdzade R, Soleymani F, Amirsalari S. Inequality in Care System Responsiveness to Children with Developmental Disability. Social Welfare Quarterly. 2008;8(30):10216.

16. Taheri Tajani P, Azadbakht M. Psychometric Properties of the Persian Version of the Activities of Daily Living Scale and Instrumental Activities of Daily Living Scale in elderly. J Mazandaran Univ Med Sci. 2016;25(132):103-12.

17. Bramesfeld $A$, Wedegärtner F, Elgeti H, Bisson S. How does mental health care perform in respect to service users' expectations? Evaluating inpatient and outpatient care in Germany with the WHO responsiveness concept. BMC Health Serv Res. 2007;7:99.

19. Karami-Tanha F, Fallah-Abadi H. Health system responsiveness for care of patients with heart failure: evidence form a university hospital. Arch Iran Med. 2014;17(11):736-40.

20. Ebrahimipour H, Vafaei Najjar A, Khanijahani A, Pourtaleb A, Javadi M, Rezazadeh A, et al. Health system responsiveness: a case study of general hospitals in Iran. Int J Health Policy Manag. 2013;1(1):99-105.

20. Mohammadi A, Kamali K. Patients' Perspectives on Responsiveness in Outpatient Clinics of Hospitals at Zanjan University of Medical Sciences. PCNM. 2015;5(1):80-92.

21. Puentes-Rosas E, Ruelas E, Martínez-Monroy T, Garrido-Latorre F. Responsiveness of the Mexican health system. Salud publica Mex. 2004;47Suppl1:12-21.

22. Mohammadi A, Kamali K. Responsiveness in the healthcare settings: A survey of inpatients. IJHR. 2014;3(3):123-32.

23. Peltzer K, Phaswana-Mafuya N. Patient experiences and health system responsiveness among older adults in South Africa. Glob Health Action. 2012;(5)18545.

24. Liabsuetrakul T, Petmanee P, Sanguanchua S, Oumudee N. Health system responsiveness for delivery care in Southern Thailand. Int J Qual Health care. 2012;24(2):169-75.

25. Forouzan AS. Assessing Responsiveness in the Mental Health Care System: the Case of Tehran. Umeå: Umeå University; 2015.pp.122.

26. Asadi-Lari M, Khosravi A, Nedjat S, Mansournia M, Majdzadeh R, Mohammad K, et al. Socioeconomic status and prevalence of selfreported diabetes among adults in Tehran: results from a large population-based cross-sectional study (Urban HEART-2). J Endocrinol invest. 2016;39(5):515-22.

27. World Health Organization, World Bank. World report on disability. Geneva: World Health Organization; 2011.pp.1-311

28. Hussein SH, Almajran A, Albatineh AN. Prevalence of health literacy and its correlates among patients with type II diabetes in Kuwait: A population based study. Diabetes Res Clin Pract. 2018;(141):118-25. doi: 10.1016/j.diabres.2018.04.033.

29. Coughlin SS, Stewart JL, Young L, Heboyan V, De Leo G. Health literacy and patient web portals. Int J Med Inform. 2018;(113):43-48.

30. Fiorentini G, Ragazzi G, Robone S. Are bad health and pain making us grumpy? An empirical evaluation of reporting heterogeneity in rating health system responsiveness. Soc Sci Med. 2015;(144):48-58.

31. Foverskov E, Holm A. Socioeconomic inequality in health in the British household panel: Tests of the social causation, health selection and the indirect selection hypothesis using dynamic fixed effects panel models. Soc Sci Med. 2016;150:172-83.

32. Allin S, Masseria C, Sorenson C, Papanicola I, Mossialos E. Measuring inequalities in access to health care: a review of the indices? Brussels: European Commission; 2007.pp.1-24. 